\title{
OLAHRAGA BAGI ATLET DIFABEL
}

\author{
Waluyo \\ Universitas Sebelas Maret Surakarta
}

\section{A. SEJARAH OLAHRAGA BAGI ATLET DIFABEL}

Ajang prestasi olahraga lebih familiar bagi para atlet sejati yang berlaga di arena pertandingan olahraga pada umumnya dan jarang menyebutnya sebagai sarana unjuk kebolehan bagi penyandang cacat. Saat ini bila kita meneliti lebih jauh ke dalam dunia penyandang cacat, maka akan kita temukan nuansa yang sama di dalam kompetisi olahraga. Ajang prestasi olahraga tidak lagi menjadi milik orang normal tetapi juga milik para penyandang cacat. Dari mulai tingkat Internasional hingga ke tingkat Daerah telah melaksanakan pertandingan olahraga penyandang cacat. Berikut ini adalah sejarah dimulainya olahraga untuk orang-orang difabel :

1. Tahun 1870, olahraga base ball pertama kali di perkenalkan di SLB tunarungu di Ohio.

2. Tahun 1885, diperkenalkan olahraga sepakbola ala amerika di kalangan siswa sekolahsekolah di Illinois. Sepakbola menjadi pelajaran olahraga utama di SLB tunarungu diakhir abad ini.

3. Tahun 1906, diperkenalkan pertama kali olahraga bola basket di SLB Wisconsin. Perkumpulan dari SLB tunarungu ini, tercatat sebagai tim penantang yang tangguh bagi sekolah umum lainnya.

4. Tahun 1924, dilaksanakan kompetisi formal internasional di luar program sekolah. Kompetisi bagi para tunarungu ini pertama kali dilaksanakan di Paris dan di ikuti oleh 9 negara.

5. Tahun 1945, AAAD (American Athletic Association for the Deaf) mendirikan, dan mem-promosikan kompetisi olahraga bagi orang yang mempunyai kelainan pendengaran.

6. Tahun 1907 Dilaksanakan pertemuan antara sekolah Overbrook dan Baltimore untuk menentukan juara bagi setiap penyandang tunanetra yang bertanding dalam kompetisi olahraga.

7. Tahun 1900, Sir Ludwig Guttman (Bapak Kursi Roda Dunia) dari Stoke Mandeville, Inggris sedikit demi sedikit memperkenalkan pertandingan olahraga sebagai bagian intergral dari rehabilitasi para veteran penyandang cacat korban peperangan.

8. Tahun 1949, Universitas Illinois menyelenggarakan pertandingan bola basket kursi roda untuk pertama kali. Sekaligus menghasilkan peraturan permainan bola basket kursi roda (National Wheelchair Basketball Association = NWBA). 
9. Tahun 1950, Ben Lipton mendirikan National Wheelchair Athletic Association (NWAA), juga mensponsori pertandingan olahraga untuk individu penyandang cacat spinal cord, dan pengguna kursi roda Iainnya.

10. Tahun 1968, presiden Joseph P. Kennedy, Jr., mendirikan dan mempromosikan pertandingan olahraga khusus penyandang tunagrahita. Diakhir abad ke 20 telah banyak didirikan perkumpulan-perkumpulan olahraga penyandang cacat multi even untuk tunanetra, tunagrahita, CP, cedera otak, stroke, dwarfism, dan les autres seperti: American Association of Adapted Sports Programs (AAASP), Adapted Sports Programs in Recreation and Education (ASPIRE). Dan American Association for Adapted Lifestyles and Fitness (AAALF).

Berikut ini adalah tokoh-tokoh yang berjasa dalam dunia pendidikan jasmani dan olahraga bagi kaum difabel :

1. Sir Ludwig Guttman, beliau dikenal sebagai Bapak Kursi Roda Dunia

2. David M. Auxter dari Universitas Slippery Rock Pennsylvania

3. Lawrence Rarick dari Universitas California di Barkeley

4. Julian U. Stein, dari Aliansi kesehatan, pendidikan jasmani, rekreasi dan dansa universitas Goerge Mason

5. Thomas M. Vodola dari Township of Ocean School District di New Jersey, Janet Wessel, dari Universitas Michigan

6. David Beaver dari Universitas Western Illinois

7. Gudrun Doll Tepper dari Universitas Berlin,

8. John Dunn dari Unversitas Oregon,

9. Claudine Sherrill dari Universitas Wanita Texas;

10. Joseph P. Winnick dari Universitas New York

11. Hideo Nakata dari Universitas Tsukuba

\section{B. SEJARAH PARALYMPIC GAMES}

Suatu hari, orang-orang dengan disabilitas / ketidakmampuan / cacat / difabel telah dikeluarkan dari kehidupan orang-orang normal, mereka dianggap telah ditakdirkan oleh Tuhan tidak normal. Mereka telah ditempatkan jauh dari kehidupan masyarakat bahkan di asingkan. Bahkan Masyarakat menyarankan mereka untuk dibunuh (karena dianggap membebani kehidupan dan mempunyai kehidupan yang membosankan). Sekenario itu berubah ketika Ludwig Guttmann (ahli bedah saraf \& ahli ilmu mengenai syaraf) datang ke Negara Inggris dari Negara Jerman. Diperintahkan menjadi director pada bagian yang menangani cedera tulang belakang di rumah sakit Stoke Mandeville. Pada saat itu, tak seorangpun tahu, apa yang harus dilakukan terhadap veteran - veteran perang yang sakit dan menderita cacat tubuh. Bahkan mereka dianggap sedang menunggu kematian, tetapi tidak lama kemudian metode penanganan rehabilitasi secara traditional dilakukan, penanganan 
melalui pendekatan psychologi sangat diperlukan untuk para tentara dan orang-orang korban perang tersebut. Sir Ludwig Guttman kemudian mendirikan pusat penaganan orang-orang cacat di Rumah Sakit Mandevile pada tahun 1944. Ia adalah seorang yang jenius yang memikirkan bagaimana sports/olahraga menjadi bagian yang integral dari sebuah perlakuan,untuk merehabilitasi pasien yang menderita cacat tubuh. Setiap hari ia melakukan observasi terhadap para tentara yang sedang sakit yang berbaring di tempat tidur tanpa bergerak, tentara-tentara tersebut merasa putus asa. Kemudian ia meminta kepada para perawat untuk memindahkan para pasien. Ia menyatakan bahwa mereka dapat bergerak. Mulai dari melempar bola yang seukuran dengan bola tenis dan menyuruh kepada mereka untuk menangkap dan melemparkannya kembali. Ia mengatakan kepada mereka bahwa mereka dapat melakukan aktivitas seperti orang lain dan kemudian Ia membentuk kelas untuk rekreasi. Aktivitas yang bersifat rekresi tersebut dibentuk di Rumah Sakit Mandaville.

Sir Ludwig Guttman membentuk Pertandingan olahraga yang pertama kali adalah Stoke Mandeville Games pada tahun 1948. Cabang Olahraga yang pertama adalah (memanah) archery. Kemudian secara bertahap atletik, bola basket, anggar, snooker, tennis meja \& renang. Dan mulai menuju pertandingan international dengan peserta dari belanda pada tahun 1954.

Kemudian pada tahun1960 di Roma, Pertama kali Stoke Mandeville games atau merupakan awal titik balik dari paralympic games di bentuk. Pada tahun 1988 paralympic games diselenggarakan dikota yang sama dengan olympic game, yang dimulai dari penyelelenggaraan olympipic Games di Seoul,Korea Selatan. Pada tahun 2001terjadi kesepakatan atau MOU antara IPC \& IOC- yang menyatakan bahwa Kota tempat penyelenggaraan untuk Olympics Games HARUS digunakan juga untuk Paralympics Games, kesepakatan tersebut terjalin hingga sekarang ini, pada tahun 2012 saat diselenggarakan Olympics Games di London Inggris ditempat yang sama juga diselenggarakan Paralympics Games, hal tersebut juga akan dilaksanakan juga pada waktu penyelenggaraan Olympics Games dan Paralympics Games 2016 di Rio de Janeiro Brazil.

Melihat dari asal usul katanya, paralympic games berarti parallel (setara/sejajar) dengan Olympic Games, dan bukan berasal dari kata paraplegia atau paralysis. Makna dari kesetaraan ini salah satunya adalah adanya kesamaan hak antara olahragawan defabel (paralimpian) dengan olahragawa orang normal dalam melaksanakan dan menyelenggarakan suatu kejuaraan multi events olahraga dalam segala aspek yang menyertainya. Moto olimpiade adalah Citus, altius, Fortius. Sedangkan moto asli paralympic adalah Mind, Body, Spirit. Belakang moto paralympic ini berubah menjadi Spirit in Motion. Kedua moto tersebut mengandung arti "Menampilkan (prestasi olahraga) sebanyak apa yang dapat mereka lakukan" (Chien, 2003),

Paralympic games ini adalah pertandingan olahraga bagi para penyandang cacat dari semua jenis klasifikasi kecacatan. Ditingkat International disebut dengan istilah Paralympic Games, ditingkat Asia disebut dengan istilah Asian Para Games, ditingkat Asia Tenggara disebut dengan 
istilah Asean Para Games, dan ditingkat Nasional disebut dengan istilah Peparnas (Pekan Paralympic Nasional), bahkan sekarang ini penyelenggaraan multi events tersebut selalu diselenggarakan dengan kesetaraan juga, artinya setiap diselenggarakan multi events Olympic Games harus juga diselenggarakan Paralympic Games, ditempat yang sama dan juga menggunakan venues yang sama juga.

Bahkan sekarang ini ada istilah yang menyatakan "ELITE SPORT" di dunia, salah satu yang termasuk dalam elite sports tersebut yaitu OLYMPIC GAMES, FIFA WORLD CHAMPION, dan PARALYMPIC GAMES.

\section{IPC (INTERNATIONAL PARALYMPIC COMMITTEE)}

The International Paralympic Committee (IPC) merupakan organisasi dunia yang memayungi kegiatan olahraga penyandang cacat (paralympian ) (gerakan paralympic). IPC menyelenggarakan event olahraga Paralympic Musim Panas dan Paralympic Musim Dingin. IPC memiliki komitmen mendampingi atlet penyandang cacat (paralympic), atau disebut "paralympian" untuk mencapai prestasi olahraga dan membuka kesempatan berolahraga kepada atlet penyandang cacat (paralympic) dari tingkat pemula sampai tingkat elit. Disamping itu, IPC bertujuan mengangkat nilai-nilai paralympic yakni keberanian, tekad inspirasi dan persamaan.

IPC didirikan pada tanggal 22 September 1989 di Dusseldorft, Jerman. IPC merupakan organisasi Internasional non-profit yang beranggotakan 162 National Paralympic Committee (NPC). Kantor pusat dan tim manajemen berlokasi di Bonn, Jerman.

Gambar 1. logo IPC

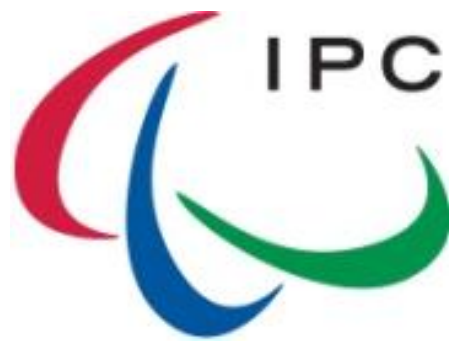

Nama logo : AGITOS

Bahasa Latin AGITO : yang berarti saya bergerak/berjuang (menyimbolkan atlet Paralympic), yang berarti bergerak Mengelilingi titik pusat, menekankan bahwa peran IPC telah membawa atlet dari seluruh penjuru dunia bersamasama dan memungkinkan mereka untuk bersaing, Mereka selalu bergerak maju dan tidak pernah menyerah.

Warna : merah, biru dan hijau (diambil dari warna bendera yang banyak dipakai negara-negara di seluruh dunia) 
STRUKTUR ORGANISASI BADAN OLAHRAGA BAGI DISABILITAS SECARA INTERNASIONAL adalah sebagai berikut :
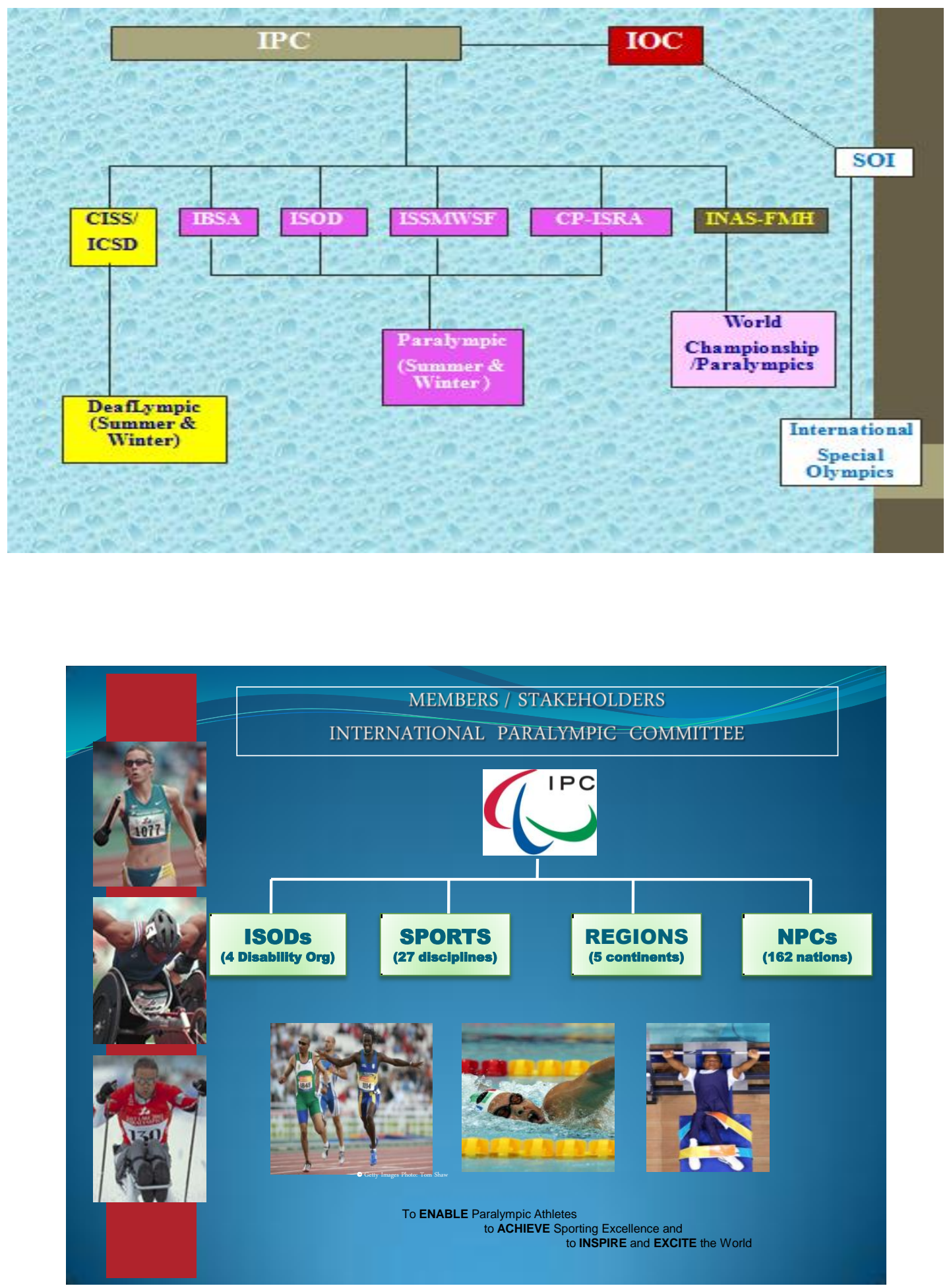


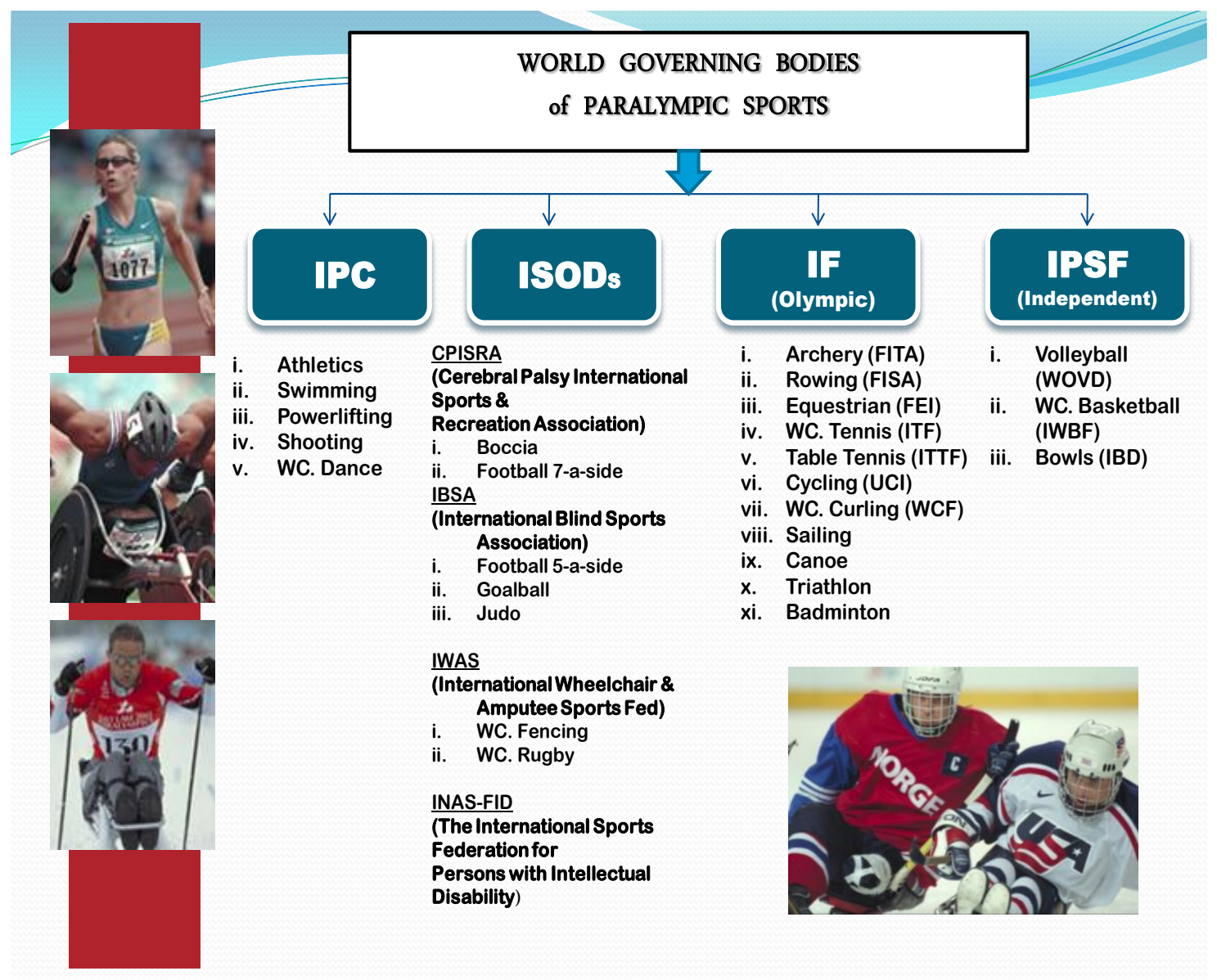

\section{SEJARAH SINGKAT NPC INDONESIA (NATIONAL PARALYMPIC COMMITTEE OF INDONESIA)}

1. Organisasi ini didirikan di Surakarta tanggal 31 Oktober 1962 yang pertama kali bernama Yayasan Pembina Olahraga Cacat (YPOC) dan terus ada serta berlangsung untuk waktu yang tidak terbatas.

2. Berdasarkan atas saran Pengurus KONI Pusat, Menteri Pemuda dan Olahraga RI, Menteri Sosial RI dan pihak-pihak terkait maka YPOC perlu ditingkatkan kedudukannya menjadi Organisasi Payung Olahraga Cacat Indonesia dengan terlebih dahulu mengubah status Yayasan menjadi organisasi sosial kemasyarakatan.

3. Dalam Musyawarah Olahraga Nasional (Musornas YPOC ke VII tanggal 31 Oktober sampai dengan 1 November 1993 di Yogyakarta, maka wadah tersebut kemudian 
ditetapkan dengan nama baru yaitu Badan Pembina Olahraga Cacat Indonesia (BPOC) sebagai kelanjutan dari YPOC.

4. Dalam Musyawarah Olahraga Nasional (Musornas) X BPOC tanggal $18-20$ November 2008 di Surakarta, atas saran Menteri Pemuda dan Olahraga RI serta mengikuti aturan lembaga-lembaga Paralympic Regional dan Internasional, maka BPOC perlu ditingkatkan eksistensi dan kedudukannya bahwa BPOC tingkat Pusat merupakan National Paralympic Committee (NPC) sehingga disebut BPOC dan atau NPC Indonesia.

5. Dalam Musyawarah Olahraga Nasional Luar Biasa tanggal 28 Juli 2010 di Surakarta dilakukan perubahan nama dari BPOC yang dulunya YPOC berubah nama menjadi NPC of Indonesia, karena mengikuti regulasi Internasional, tidak diperkenankan menggunakan istilah cacat.

6. Visi :

Terwujudnya kesetaraan dan keseimbangan pembinaan olahraga penyandang cacat (paralympian)

7. Misi :

1). Mengatur dan memberikan bimbingan dalam pelaksanaan pelatihan olahraga penyandang cacat (paralympic).

2). Mengusahakan dan mengatur pembiayaan kegiatan olahraga penyandang cacat (paralympic).

3). Mengatur kegiatan olahraga penyandang cacat (paralympic) baik ditingkat daerah, nasional maupun Internasional.

4). Mengusahakan peningkatan prestasi, kesejahteraan dan pendidikan atlet.

8. Tujuan :

1). Membentuk watak kepribadian penyandang cacat (paralympic) Indonesia yang mencintai nilai kemanusiaan, kejujuran dan ketaqwaan terhadap Tuhan Yang Maha Kuasa.

2). Mewadahi penyandang cacat (paralympic) Indonesia untuk berperan serta dalam pembangunan Nasional melalui kegiatan olahraga.

3). Mewujudkan dunia olahraga bagi penyandang cacat (paralympic) agar lebih maju, berkeadilan, bermartabat dan sejajar dengan keberadaan olahraga pada umumnya.

4). Memupuk kesatuan dan Persatuan Bangsa Indonesia serta menjalin persahabatan antar bangsa.

5). Mengharumkan nama Indonesia melalui pencapaian prestasi olahraga penyandang cacat (paralympian) ditingkat Internasional.

6). Memperkuat gerakan perjuangan untuk mewujudkan kesamaan hak dan kesempatan bagi penyandang cacat (paralympic) dalam segala aspek kehidupan dan penghidupan melalui olahraga

9. Keanggotaan NPC Indonesia pada organisasi Internasional : 
1). Anggota Asean Para Sports Federation (APSF) di Tingkat Asia Tenggara.

2). Anggota Asian Paralympic Committee (APC) di Tingkat Asia.

3). Anggota International Paralympic Committee (IPC) untuk Tingkat Dunia

10. Keanggotaan Organisasi Badan Olahraga berdasarkan Jenis Kecacatan :

1). International Sports Organization for the Disabled (ISOD).

2). International Blind Sports Association (IBSA).

3). Cerebral Palsy International Sports and Recreation Association (CP-ISRA).

4). International Stoke Mandeville Wheelchair Sports Federation (ISMWSF).

5). Committee International des Sports des Sourds (CISS).

6). International Sports Federation for Persons with Mental Handicap (INAS-FMH)

11. Pertandingan Multi Events Olahraga bagi Kaum Defabel (Paralimpian) :

1). Ajang pertandingan Olahraga penyandang cacat (paralympic) untuk tingkat dunia disebut Paralympic Games yang berlangsung dan diselenggarakan bersamaan dengan penyelenggaraan Olimpiade.

2). Ajang pertandingan Olahraga penyandang cacat (paralympic) untuk tingkat Asia disebut Asian Para Games yang berlangsung dan diselenggarakan bersamaan dengan penyelenggaraan Asian Games.

3). Ajang pertandingan Olahraga penyandang cacat (paralympic) untuk tingkat Kawasan Asia Tenggara disebut Asean Para Games yang berlangsung dan diselenggarakan bersamaan dengan penyelenggaraan Sea Games.

4). Ajang Pertandingan Olahraga penyandang cacat (paralympic) untuk tingkat Nasional di Indonesia disebut Pekan Paralympic Nasional (PEPARNAS) yang berlangsung dan diselenggarakan bersamaan dengan Pekan Olahraga Nasional (PON).

5). Ajang Pertandingan Olahraga Cacat untuk tingkat provinsi disebut Pekan Paralympic Provinsi (PEPARPROV) yang berlangsung dan diselenggarakan bersamaan dengan penyelenggaraan Pekan Olahraga Provinsi (PORPROV) tingkat Provinsi.

6). Ajang Pertandingan Olahraga Cacat untuk tingkat Kabupaten/Kota disebut Pekan Paralympic Kabupaten/Kota (PEPARKAB/PEPARKOT) yang berlangsung dan diselenggarakan bersamaan dengan Pekan Olahraga Kabupaten/Kota (PORKAB/PORKOT)

\section{E. SEJARAH SINGKAT PEPARNAS (PEKAN PARALYMPIC NASIONAL) DI INDONESIA.}

Peparnas merupakan penyelenggaraan pertandingan dan kompetisi multi events, semua cabang olahraga bagi kaum defabel terbesar di Indonesia. Istilah Peparnas merupakan pergantian dari istilah PORCANAS, yang merupakan perpanjangan dari Pekan Olahraga Cacat Nasional. Regulasi Internasional sekarang ini telah melarang penggunaan kata "cacat" 
dalam penggunaan kata pada semua events yang diselenggarakan, karena istilah cacat dianggap memarginalkan sebagian kaum/manusia yang berbeda. Oleh kerena hal tersebut NPC Indonesia merubah istilah PORCANAS menjadi "PEPARNAS".

Peparnas merupakan ajang pembuktian prestasi bagi olahragawan defabel yang bersekala nasional. Mereka mewakili Provinsi dan sekaligus NPC Pengprov masing-masing daerah. Peparnas mempertandingkan cabang-cabang olahraga yang resmi mengikuti regulasi cabang olahraga yang dipertandingkan di IPC (International Paralympic Committee) yang saat ini jumlah cabang olahraga di IPC sudah berkembang sebanyak 26 cabang olahraga. NPC Indonesia, selaku anggota dari IPC juga telah mengikuti regulasi tersebut, akan tetapi cabang olahraga yang saat ini sudah dibina di Indonesia baru berkembang sekitar 13 cabang olahraga. Oleh karena itu penyelenggaraan Peparnas di Bandung Jawa Barat, NPC Indonesia baru dapat mempertandingkan 13 cabang olahraga, dan setiap 4 tahun sekali NPC Indonesia terus berusaha untuk menambah minimal 1 cabang olahraga disetiap penyelenggaraan Peparnas.

Berdasarkan regulasi internasional penyelenggaraan Peparnas sekarang ini menjadi satu paket dengan penyelenggaraan Pekan Olahraga Nasional bagi olahragawan able/olahragawan normal, yang dalam hal ini di Indonesia sudah sangat familier disebut dengan istilah PON (Pekan Olahraga Nasional). Penyelenggaraan PON (Pekan Olahraga Nasional) di Indonesia sudah berjalan empat tahun sekali, masyarakat Indonesia sudah terbiasa mendengar dan sudah tahu tentang penyelenggaraannya, akan tetapi penyelenggaraan PEPARNAS yang sekarang ini sudah berjalan juga empat tahun sekali, masyarakat awam belum begitu mengenal dan mengetahujnya.

Penyelenggaraan Peparnas di Indonesia sebenarnya telah berlangsung sebanyak 15 kali, dan akan menuju yang ke-16 kali di Propinsi Papua yang akan datang, akan tetapi penyelenggaraan events yang besar dan pelaksanaannya disamakan dengan penyelenggaraan PON, masyarakat di Indonesia belum bayak tahu akan penyelenggaraan tersebut, olehkarena itulah kami menulis makalah ini agar masyarakt olahraga tahu akan penyelenggaraan ini. Penyelenggaraan PORCANAS ke-12 di Palembang Sumatera Selatan tahun 1998, sampai dengan namanya diganti dengan PEPRNAS Papua 2020 yang akan dating, perlu diketahui oleh masyarakat olahraga di Indonesia. Berikut ini adalah sejarah penyelenggaraan Peparnas di Indonesia : 


\section{PENYELENGGARAAN PEPARNAS}

\begin{tabular}{|c|c|c|c|c|c|}
\hline No & Pelaksanaan Ke & Tahun & Tuan Rumah & Juara Umum & Ket \\
\hline 1 & I & 1957 & SURAKARTA-JATENG & JAWA TENGAH & RC. Surakarta \\
\hline 2 & $\|$ & 1959 & SURAKARTA & JAWA TENGAH & RC. Surakarta \\
\hline 3 & III & 1964 & SURAKARTA & JAWA BARAT & YPOC \\
\hline 4 & IV & 1969 & YOGYAKARTA & JAWA BARAT & YPOC \\
\hline 5 & V & 1972 & BANDUNG & DKIJAKARTA & YPOC \\
\hline 6 & VI & 1975 & UJUNG PANDANG & SULAWESI SELATAN & YPOC \\
\hline 7 & VII & 1980 & SURAKARTA & DKIJAKARTA & YPOC \\
\hline 8 & VIII & 1984 & SURAKARTA & JAWA TENGAH & YPOC \\
\hline 9 & IX & 1988 & MALANG & DKIJAKARTA & YPOC \\
\hline 10 & $x$ & 1993 & YOGYAKARTA & DKI JAKARTA & $B P O C$ \\
\hline 11 & $X I$ & 1998 & BANDUNG & JAWA BARAT & $B P O C$ \\
\hline 12 & X\| & 2004 & PALEMBANG & JAWA BARAT & $B P O C$ \\
\hline 13 & $X\|\|$ & 2008 & KALTIM, SAMARRNDA & JAWA TENGAH & $B P O C$ \\
\hline 14 & XIV & 2012 & PEKANBARU, RIAU & & $\mathrm{NPCl}$ \\
\hline 15 & XV & 2016 & BANDUNG & & $\mathrm{NPCl}$ \\
\hline
\end{tabular}




\section{Cabang Olahraga \& Jumlah Nomor Pertandingan}

\begin{tabular}{|c|c|c|c|c|}
\hline No & $\begin{array}{l}\text { Porcanas/ } \\
\text { Peparnas ke }\end{array}$ & Cabang Olahraga & Nomor Pertandingan & Ket \\
\hline \multirow[t]{9}{*}{1} & \multirow{8}{*}{$\begin{array}{l}\text { Tahun } 2004 \text { ke } \\
\text { XII di } \\
\text { Palembang }\end{array}$} & Atletik & 155 & \\
\hline & & Renang & 100 & \\
\hline & & Bulutangkis & 8 & \\
\hline & & Tenis Meja & 36 & \\
\hline & & Catur & 4 & \\
\hline & & Angkat Berat & 14 & \\
\hline & & Tenis Lapang Kursi Roda & 4 & \\
\hline & & Sepakbola & 1 & \\
\hline & \multicolumn{2}{|c|}{ Total Nomor Pertandingan } & 322 & \\
\hline
\end{tabular}

\begin{tabular}{|c|c|c|c|c|}
\hline No & $\begin{array}{l}\text { Porcanas/ } \\
\text { Peparnas ke }\end{array}$ & Cabang Olahraga & Nomor Pertandingan & Ket \\
\hline \multirow[t]{8}{*}{2} & \multirow{8}{*}{$\begin{array}{l}\text { Tahun } 2008 \text { ke } \\
\text { XIII di } \\
\text { Kalimantan } \\
\text { Timur }\end{array}$} & Atletik & 168 & \\
\hline & & Renang & 50 & \\
\hline & & Bulutangkis & 22 & \\
\hline & & Tenis Meja & 35 & \\
\hline & & Catur & 12 & \\
\hline & & Angkat Berat & 20 & \\
\hline & & Tenis Lapang Kursi Roda & 6 & \\
\hline & & Sepakbola & 1 & \\
\hline & \multicolumn{2}{|c|}{ Total Nomor Pertandingan } & 314 & \\
\hline
\end{tabular}




\begin{tabular}{|c|c|c|c|c|}
\hline No & $\begin{array}{c}\text { Porcanas/ } \\
\text { Peparnas ke }\end{array}$ & Cabang Olahraga & Nomor Pertandingan & Ket \\
\hline \multirow[t]{9}{*}{3} & \multirow{9}{*}{$\begin{array}{l}\text { Tahun } 2012 \text { ke } \\
\text { XIV di } \\
\text { Pekanbaru-Riau }\end{array}$} & Atletik & 185 & \\
\hline & & Renang & 117 & \\
\hline & & Bulutangkis & 48 & \\
\hline & & Tenis Meja & 90 & \\
\hline & & Catur & 12 & \\
\hline & & Angkat Berat & 20 & \\
\hline & & Tenis Lapang Kursi Roda & 19 & \\
\hline & & Futsal & 1 & \\
\hline & & Bola Volley Duduk & 2 & \\
\hline \multicolumn{3}{|c|}{ Total Nomor Pertandingan } & 494 & \\
\hline
\end{tabular}

\begin{tabular}{|c|c|c|c|c|c|c|c|c|c|c|c|c|}
\hline \multirow{3}{*}{ 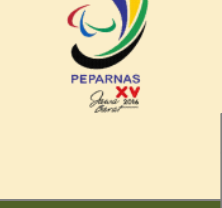 } & \multicolumn{12}{|c|}{$\begin{array}{c}\text { NOMOR LOMBA \& MEDALI } \\
\text { Peparnas XV-2016 Jawa Barat }\end{array}$} \\
\hline & \multicolumn{8}{|c|}{ NOMOR PERTANDINGAN } & \multirow{2}{*}{\multicolumn{4}{|c|}{$\begin{array}{l}\text { JUMLAH KEPING MEDAL } \\
\text { YANG HARUS } \\
\text { DISEDIAKAN } \\
\end{array}$}} \\
\hline & \multicolumn{2}{|c|}{ TUNGGAL } & \multicolumn{2}{|c|}{ GANDA } & \multirow{2}{*}{ MIX } & \multicolumn{2}{|c|}{ BEREGU } & \multirow{2}{*}{ SUM } & & & & \\
\hline CABOR & PA & PI & PA & PI & & PA & PI & & EMAS & PERAK & PRG & SUM \\
\hline 1 Angkat Berat & 10 & 10 & & & & & & 20 & 20 & 20 & 20 & 60 \\
\hline 2 Atletik & 130 & 82 & & & & & & 212 & 245 & 245 & 245 & 735 \\
\hline 3 Bolavoli Duduk & 1 & 1 & & & & & & 2 & 30 & 30 & 30 & 90 \\
\hline 4 Bulutangkis & 6 & 6 & 4 & 2 & 2 & & & 20 & 33 & 33 & 66 & 132 \\
\hline 5 Catur & 9 & 9 & & & & 8 & 8 & 34 & 34 & 34 & 34 & 102 \\
\hline 6 Goalball & 1 & 1 & & & & & & 2 & 20 & 20 & 40 & 80 \\
\hline 7 Judo & 7 & 5 & & & & & & 12 & 12 & 12 & 24 & 48 \\
\hline 8 Panahan & 22 & 9 & & & & & & 31 & 56 & 56 & 56 & 168 \\
\hline 9 Renang & 102 & 58 & & & & & & 160 & 160 & 160 & 160 & 480 \\
\hline 10 Sepakbola CP & 1 & & & & & & & 1 & 20 & 20 & 40 & 80 \\
\hline $\begin{array}{ll}11 & \begin{array}{l}\text { Tenis Lapang Kursi } \\
\text { Roda }\end{array}\end{array}$ & 3 & 2 & 2 & 2 & 3 & 1 & 1 & 14 & 32 & 32 & 64 & 128 \\
\hline 12 Tenis Meja & 11 & 11 & 7 & 5 & 7 & 6 & 4 & 51 & 102 & 102 & 204 & 408 \\
\hline 13 Tenpin Bowling & 4 & 4 & 4 & 3 & 7 & 3 & 3 & 28 & 54 & 54 & 54 & 162 \\
\hline JUMLAH & 279 & 171 & 4 & 2 & 2 & 8 & 8 & 474 & 818 & 818 & 1037 & 2673 \\
\hline
\end{tabular}




\section{DAFTAR PUSTAKA}

Dougherty, N. J., David, A., Goldberger, A. S. \& Heinzmann, G. S. (1994). Sport Physica

Achmad Zuhal, Kekuatan Daya Saing Indonesia; Mempersiapkan Masyarakat Berbasis Pengetahuan. Jakarta: Kompas, 2008.

Bratakusumah, Deddy S.(2008). Pengembangan Kelembagaan dan Sarana Prasarana pembinaan Pemuda dan Olahraga. Makalah Diskusi. Jakarta: BappenasKemenegpora

Helmut Digel, Sport in a Changing Society, Verlag Karl Hoffman, Jerman, 1995.

Kiram, Yanuar. (2008). Peningkatan Kapasitas dan Kualitas SDM Dalam mendukung pembangunan Pemuda dan Olahraga. Makalah Diskusi. Jakarta: BappenasKemenegpora

Mutohir, Toho Cholik. (2008). Identifikasi Permasalahan, Peluang, dan Tanatangan pembangunan keolahrgaan 5 tahun kedepan. Makalah Diskusi. Jakarta: BappenasKemenegpora

Mutohir, Toho Cholik, Sport Development Index: Konsep, Metodologi, dan Aplikasi, Kementerian Negara Pemuda dan Olahraga RI, Jakarta, 2007

Prayitno, Irwan (2008). Refleksi Pembangunan Pemuda dan Olahraga di Indonesia (Kebijakan dan Strategi). Makalah Diskusi. Jakarta: Bappenas-Kemenegpora

Soecipto, Ahmad (2008). Program Atlet Andalan (PAL) Renstra 2008-2012. Makalah Diskusi. Jakarta: Bappenas-Kemenegpora

Vanlandewijck YC, Daly DJ, Theisen DM. Field test evaluation of aerobic, anaerobic, and wheelchair basketball skill perfor- mances. Int J Sports Med. 1999;20(8):548-54.

Vanlandewijck YC, Evaggelinou C, Daly DJ, et al. The relationship between functional potential and field performance in elite female wheelchair basketball players. J Sports Sci. 2004;22(7):668-75.

Vanlandewijck YC, Spaepen AJ, Lysens RJ. Wheelchair pro- pulsion: functional ability dependent factors in wheel- chair basketball players. Scand J Rehabil Med. 1994;26(1): 37-48.

Veeger HE, Hadj Yahmed M, van der Woude LH, Charpentier P. Peak oxygen uptake and maximal power output of Olym-pic wheelchair-dependent athletes. Med Sci Sports Exerc. 1991;23(10):1201-9.

Wasserman K. The anaerobic threshold: definition, physiological significance and identification. Adv Cardiol. 1986;35:1-23. 